\title{
First record of Hypsugo cf darwinii (Tomes, 1859) in Tuscany, Italy
}

\author{
Dondini Gianna ${ }^{1,2}$, Vergari Simone ${ }^{1,2}$, Fichera Gaetano $^{3}$, Kiefer Andreas $^{3}$ \\ ${ }^{1}$ Centro Naturalistico e Archeologico dell'Appennino Pistoiese \\ via L. Orlando 100, I-51028 Campo Tizzoro, Pistoia, (Italy). \\ ${ }^{2}$ Itinerari Società Cooperativa, Via Geri Fiorini 294a, 51028 Gavinana (Italy). \\ ${ }^{3}$ Department of Biogeography, Trier University, Trier (Germany). \\ *Corresponding author: sim.vergari@gmail.com
}

DOI: http://dx.doi.org/10.14709/BarbJ.9.1.2016.01 (C) 2016 Published by SECEMU.

Spanish title: Primera cita de Hypsugo cf darwinii (Tomes, 1859) en Toscana, Italia

\begin{abstract}
Hypsugo darwinii was originally described in the Canary material supplied by Darwin and attributed later to Hypsugo savii, but recent genetic studies have instead highlight edits new systematic position. It is distributed in North Africa, the Canary Islands, Sicily and Sardinia. Research carried out on Montecristo Island (Tuscan Archipelago National Park) in 2015, revealed the presence of this species on this island, the first for Tuscany, thus providing the new northernmost limit of its distribution. Our results also highlight the importance of small isolated islands for the conservation of bat biodiversity, particularly in the Mediterranean basin.
\end{abstract}

Key words: Cryptic species, 16S, distribution, Montecristo Island.

Hypsugo cf darwinii (Tomes, 1859) is a bat species originally described for the Canary material and reported for a large portion of North Africa, Canary Islands, Sicily, and Sardinia (Veith et al. 2011). This different lineage was proposed as new species by Mayer et al. 2007, according to mitochondrial DNA sequences, although it is still in need of a modern morphological description. Accordingly, at present time, it is not possible to discriminate between the taxa $H$. cf darwinii and Hypsugo savii (Bonaparte, 1837) on the only basis of morphology. Genetic markers are necessary for the identification of this species (e.g., 16S or ND1: Veith et al. 2011). Despite the unclear status of its species rank, we followed Mayer et al. 2007, waiting for further studies ,e.g. using nuclear markers, that will enlighten the definitive rank of this lineage.

As part of aresearch on bats of Montecristo Island (Tuscan

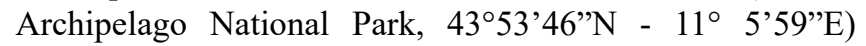
(Fig.1), on $8^{\text {th }}$ June 2015, two individuals were captured with a mist net along a narrow valley with rainwater puddles, at an altitude of about $180 \mathrm{~m}$ a.s.l.

Montecristo is a granite, entirely mountainous island of $10.39 \mathrm{sq} \mathrm{km}$ located $65 \mathrm{~km}$ from the Italian mainland and 60 $\mathrm{km}$ from Corsica, with a maximum height of $645 \mathrm{~m}$ (Monte della Fortezza).
The female individual, captured at 9.40 p.m., was in an excellent physical condition, with well developed mammae and visible nipples (presumably lactating). The following measures were taken: weight $6,2 \mathrm{~g}$; forearm $33,9 \mathrm{~mm}$; length of the fifth finger (D5): $40,7 \mathrm{~mm}$. The male was captured at 9.50 p.m. The following measures were taken: weight 5,3 $\mathrm{g}$; forearm $33 \mathrm{~mm}$; length of the fifth finger (D5): 40,4 mm.

Both individuals had dark skin contrasting with dorsal light brown pelage, and a small reddish brown spot between the ears, the corners of mouth and the shoulders (Fig.1).

Both individuals were photographed and their ultrasounds recorded when hand-released. Five other recordings were made while individuals were flying. Recordings were made through a Pettersson Elektronik D-240X Ultrasound Detector, connected to an Edirol R-09. The resulting sequences were then analysed (through the software BatSound 3.10) using a sampling frequency of $44.1 \mathrm{kHz}$ and a $512 \mathrm{pt}$ FFT. The comparison with the acoustic measures of the closely related Hypsugo savii (Russo \& Jones 2002, Papadatou et al. 2008, Barataud 2015) showed that the two taxa seem to echolocate using almost identical calls, a factor which may increase the difficulties to define and study $H$. cf darwinii (Table 1 ). Tissue samples were collected with a sterile biopsy punch of $3 \mathrm{~mm}$ in diameter to discriminate correctly the species: a genetic analysis was then performed. Molecular samples of the 2 


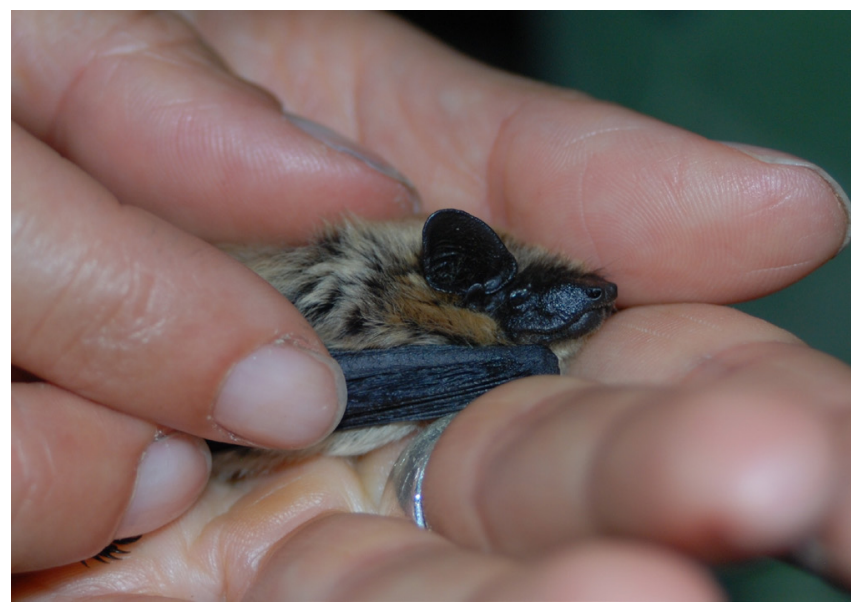

Fig. 1 - Female of Hypsugo cf darwinii, Montecristo Island. The reddish brown spot under the ear is evident.

individuals allowed the taxonomic identification through a comparison with the deposit sequences in GenBank.

We sequenced about 560 bp of the mitochondrial $16 \mathrm{~S}$ ribosomal gene using the $16 \mathrm{SPle} 1+\left(5^{\prime} \mathrm{ACA}\right.$ TCACCTCTAGCATAAAA-3') and 16SPle4(5'-CCGGTCTGAACTCAGATCACG-3') (Spitzenberger et al. 2006). PCR cycling procedure was the following: initial denaturation step: $120 \mathrm{~s}$ at $94^{\circ} \mathrm{C}, 37$ cycles: denaturation 30 $\mathrm{s}$ at $94^{\circ} \mathrm{C}$, primer annealing for $90 \mathrm{~s}$ at $57,6^{\circ} \mathrm{C}$, extension for $180 \mathrm{~s}$ at $65^{\circ} \mathrm{C}$ and final extension for $180 \mathrm{~s}$ at $65^{\circ} \mathrm{C}$.

Sequences were aligned and comparedusing the software Mega version 7 (Kumar et al. 2015), including sequences by Veith et al., 2011. The female belonged to the published haplotype "Hsav-II-7 Sicily"; by contrast, the male belonged to a new haplotype, different for only one base (a T substituted by a C) from the "Sicilian" one. Thus, a transition has occurred. Hereafter it will be referred to as "Hsav-II-8 Montecristo".

The discovery of this species in Tuscany increases the total number of mammal species of this region, enables us to expand the Italian and overall range of $H$. darwinii with its Northernmost report (Fig.2). Furthermore, these observations highlight the value of small islands for the conservation of biodiversity, particularly within the Mediterranean basin.

Since, we can presume that a breeding colony is present on the island as we can infer that the female was lactating, thus ranking Montecristo as the smallest island where a population of this species occur.

Since the island is roughly $60 \mathrm{~km}$ away from the closest land, it is very likely that the population living on the island is a closed population, with scarce arrivals of new individuals. Further researches will highlight if the population is effectively isolated or if further studies on Minimum Viable Population on bats should be deserved.

Considering that $H$. savii shows a broad range of fur colour (Arlettaz et al. 1993), it is possible that the lighter fur and the reddish brown spot on the shoulder is one of the possible colours within the normal range of fur patterns also in $H$. cf. darwinii and that it could be present throughout the distribution of this taxon.

However, this kind of reddish brown spot has never been observed in Sardinia (Mucedda \& Fichera pers. com.), Malta (Mifsud pers. com.), Algeria (Mourad pers. com.) and Canary Islands (Trujillo \& Barone pers.com.). On the other hand, it's not possible to exclude a partially seasonal moult, but at the moment no data are available, due to the difficulty to perform a survey all year round.

It is unlikely that these reddish brown spots are due to the facial glands. In H. savii, these glands secrete an orange oil to maintain the skin of patagium in good conditions, but orange spots have never been observed in Italy mainlandand in other Tuscan islands close to the coast (Dondini \& Vergari, personal observation). $H$. savii has buccal pads at the mouth corner and it has never been reported to have orange secrets (Dondini et al. 2003).

The presence of $H$. darwinii in an island located between Corsica and Tuscany, suggests the hypothesis that this taxon might also be present in Corsica island and in Italy mainland. Further surveys combined with molecular identification are required to assess the current occurrence of this species in the Tuscan archipelago, where Hypsugo savii has been recorded on the basis of morphologic identification (Vergari \& Dondini 1998).

Recently a mitochondrial lineage, Pipistrellus kuhlii desertii Thomas 1915, after being arisen to a species level, is now ranked as exactly an ancient divergent lineage of Pipistrellus kuhlii (Kuhl, 1817), (Andriollo et al. 2015, Benda et al. 2015). This may also be the case of Hypsugo cf darwinii, but it should be valued that the lineage $P$. $k$. desertii differs ca. 6\% from P. kuhlii (Coraman et al. 2013, Ibáñez et al. 2006), where as $H$. cf darwinii $9.6 \%$ from $H$. savii in the ND1-gene (Mayer et al. 2007).

Beside taxonomic changes, Hypsugo cf darwinii is an Evolutionary Significant Units (ESU) (Veith et al. 2011) and its occurrence should be taken into account in modern approach to biodiversity conservation. All sequences have been deposited in GenBank. (the sequences will be deposited after the acceptation of the manuscript).

Table 1. Descriptive statistics for Hypsugo cf darwinii calls in Montecristo Island (Tuscany, Italy). $\mathrm{SF}=$ start frequency; $\mathrm{EF}=$ end frequency; Fmax = frequency of maximum energy; $\mathrm{D}=$ duration; $\mathrm{SD}=$ standard deviation.

\begin{tabular}{lllll} 
& SF $(\mathbf{k H z})$ & EF $(\mathbf{k H z})$ & Fmax $(\mathbf{k H z})$ & D $(\mathbf{m s})$ \\
\hline Mean & 42,6 & 29,6 & 33,9 & 8,8 \\
SD & 3,54 & 1,62 & 0,69 & 1,51 \\
min-max & $37-48$ & $28-32$ & $33-34,9$ & $6,9-11,1$ \\
$\mathbf{n}$ & 7 & 7 & 7 & 7 \\
\hline
\end{tabular}




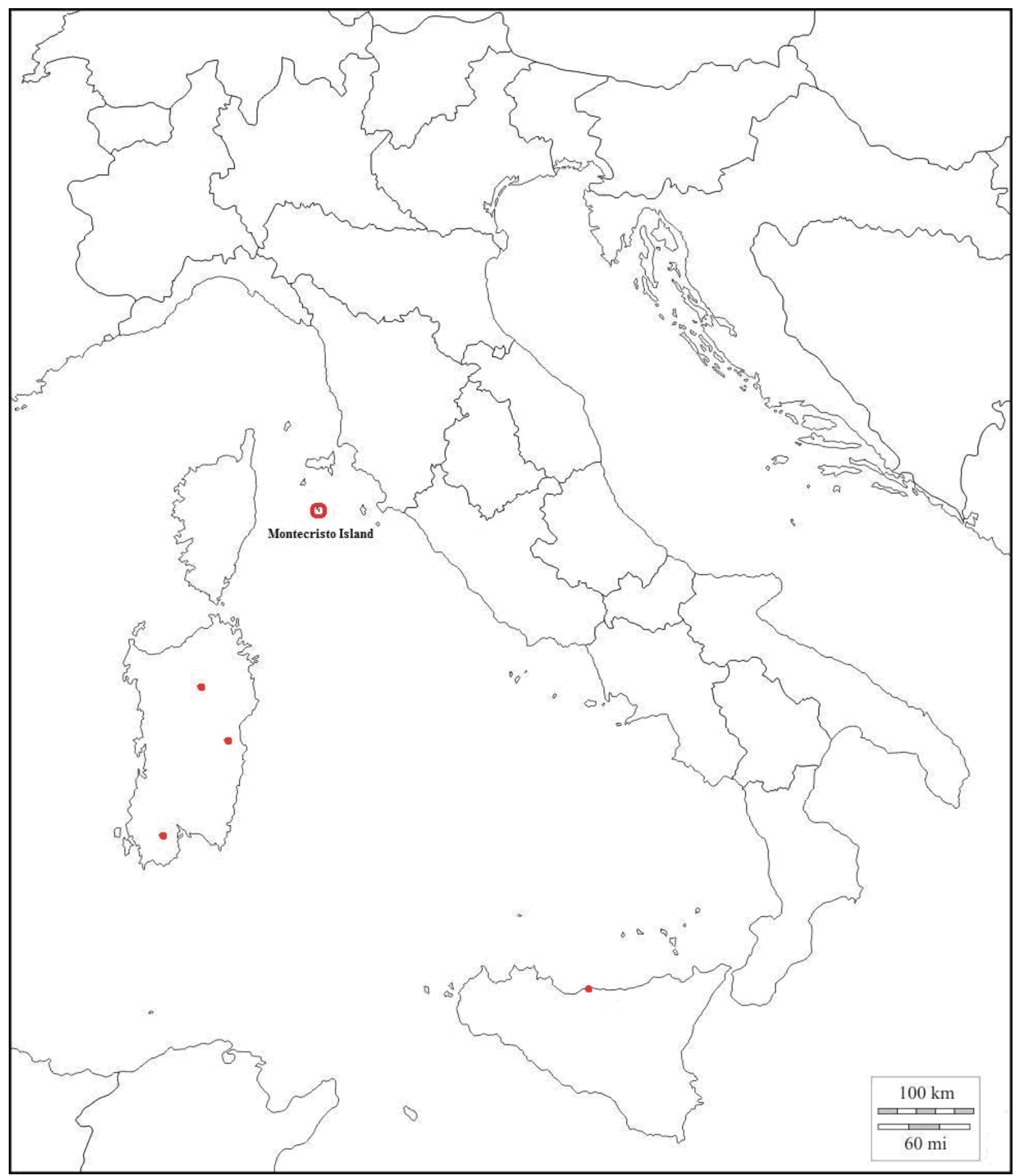

Fig. 2 - Montecristo record (red circle) and records of Hypsugo cf darwinii in Italy, based on Veith et al. 2011 (red dots).

\section{ACKNOWLEDGEMENTS}

Fieldwork was conducted under the licence of the Italian Environment Ministry ( $\left.\mathrm{n}^{\circ} 0020706-23 / 10 / 2015\right)$. We are very grateful to: Dr Giampiero Sammuri, President of Federparchi who supported our research the Italian State Forestry Service (Corpo Forestale dello Stato), Dr. Alessandro Bottacci, Dr. Marco Panella, Dr. Stefano Vagniluca and personnel of the patrol boat (Corpo Forestale dello Stato di Follonica), Dr. Franca Zanichelli Director of the Tuscan Archipelago National Park, the two guardians of the island (Giorgio
Marsiaj and Luciana Andrioli) Petra Williams for her help in laboratory, Christian Dietz for the precious comments on a previous draft. Anna Kraczyna kindly revised the English text. The association "SuccessioneEcologica"- Pandino (Cremona, Italy) provided technical help in language revision. 


\section{REFERENCES}

Arlettaz R., Guibert E., Lugon A., Médard P. \& SIERRO A. 1993.Variability of fur coloration in Savi's bat Hypsugo savii (Bonaparte, 1837). Bonner Zoologische Beiträge, 44: 293-297.

Andriollo, T., Naciri, Y. \& Ruedi, M. 2015. Two mitochondrial Barcodes for one Biological species: the case of European Kuhl's Pipistrelles (Chiroptera). PLoS ONE 10:e0134881. http://dx.doi.org/10.1371/journal. pone. 0134881

Agnelli, P., Martinoli, A., Patriarca, E., Russo D., Scaravelli, D. \& Genovesi, P. 2006. Guidelines for bat monitoring: methods for the study and conservation of bats in Italy. Quaderni Conservazione Natura, 19 bis, 1st Naz. Fauna Selvatica, Rome and Ozzano dell' Emilia (Bologna), 193 pp.

Barataud, M. 2015. Acoustic ecology of European bats. Species Identification, Studies ofTheir Habitats and Foraging Behaviour. Biotope, Mèze; Muséum national d'histoire naturelle, Paris (Inventaires et biodiversité Series), 352 pp.

Benda, P., Andriollo, T. \& Ruedi, M. 2015. Systematic position and Taxonomy of Pipistrellus deserti (Chiroptera: Vespertilionidae). Mammalia 79:419-438. http:dw.doi. org/10.1515/mammalia-2014-0024

Çoraman, E., Furman, A., Karataş, A., Bilgin, R. 2013. Phylogeographic analysis of Anatolian bats highlights the importance of the region for preserving the Chiropteran mitochondrial genetic diversity in the Western Palaearctic. Conservation Genetics 14:1205-1216. http://dx.doi.org/ 10. 1007/s10592-013-0509-4

Dondini, G., Lanza, B. \& Vergari, S. 2003.The buccal pad of bats and its seasonal cycle in Nyctalus leisleri (Kuhl, 1817) (Mammalia, Chiroptera, Vespertilionidae). Bollettino Museo regionale Scienze naturali Torino 20:105-118.
IbáÑez, C., García-Mudarra, J.L., Ruedi, M., StadelmanN, B., Juste, J. 2006. The Iberian contribution to cryptic diversity in European bats. Acta Chiropterologica 8:277-297.http://dx.doi.org/10.3161/17335329(2006)8[277:TICTCD]2.0.CO;2

LAnZA, B. 2012. Chiroptera. Fauna d'Italia. Mammalia V. Chiroptera. Edizioni Calderini, Bologna, 786 pp.

Papadatou, E., Butlin, R.K., \& Altringham, J.D. 2008. Identification of bat species in Greece from their echolocation calls. Acta Chiropterologica 10:127-143. http:// dx.doi.org/10.3161/150811008X331153

Russo, D., \& Jones, G. 2002. Identification of twentytwo bat species (Mammalia: Chiroptera) from Italy by analysis of time-expanded recordings of echolocation calls. Journal of Zoology 258:91-103 http://dx.doi.org/10.1017/ S0952836902001231

Spitzenberger, F., Strelkov, P.P., Winkler, H. \& HARING, E. 2006. A preliminary revision of the genus Plecotus (Chiroptera, Vespertilionidae) based on genetic and morphological results. Zoologica Scripta 35:187-230. http:// dx.doi.org/10.1111/j.1463-6409.2006.00224.x

Veith, M., Mucedda, M., Kiefer, A \& Pidinchedda, E. 2011. On the presence of pipistrelle bats (Pipistrellus and Hypsugo; Chiroptera: Vespertilionidae) in Sardinia. Acta Chiropterologica 13:89-99. http://dx.doi. org/10.3161/150811011X578642

Vergari, S. \& Dondini, G. 1998. La Chirotterofauna dell'Arcipelago Toscano. Serie scientifica n.5, WWF Delegazione Toscana, $109 \mathrm{pp}$. 